\title{
POR QUE OS BRASILEIROS NÃO CONFIAM NOS PARTIDOS? BASES PARA COMPREENDER A CULTURA POLÍTICA (ANTI)PARTIDÁRIA E POSSÍVEIS SAÍDAS
}

\author{
Marcello Baquero \\ Bianca de Freitas Linhares
}

\begin{abstract}
Resumo
Os partidos políticos são considerados as instituições mais importantes de mediação política entre Estado e sociedade. Assim, a função de representação é fundamental como dispositivo de fortalecimento dos valores democráticos e das instituições políticas. No entanto, a despeito de avanços significativos na dimensão formal da democracia, o Brasil continua a enfrentar obstáculos que podem minar os avanços da democracia. Neste artigo busca-se entender por que os brasileiros não confiam nos partidos, por meio de uma retrospectiva histórica e dados de pesquisas de opinião probabilística em nível nacional e estadual. Finaliza-se o artigo analisando os benefícios que podem resultar de uma integração entre a dimensão formal de representação política e dispositivos alternativos de caráter societário de envolvimento político.
\end{abstract}

Palavras-Chave: Partidos; Brasil; Democracia; Capital Social; Cultura Política.

\begin{abstract}
Political parties are considered the most important institutions of political mediation between the State and society. Thus the role of political representation is an essential component of strengthening democratic political values and political institutions. However, despite significant formal democratic advances, Brazil continues to face obstacles that could undermine those advances. In this article, we seek to understand why Brazilians don't trust political parties. The data utilized are from probabilistic opinion surveys conducted nationally and at the level of State and from a historical retrospective. We end the article analyzing the benefits that could result from a combination of formal political representation mechanisms and alternative societary forms of political involvement.
\end{abstract}

Keywords: Political Parties; Brazil; Democracy; Social Capital; Political Culture.

\section{Introdução}

Este artigo tem por objetivo examinar o papel dos partidos políticos no processo de construção da democracia contemporânea no Brasil, focalizando suas dificuldades em se institucionalizar como agências mediadoras eficientes entre Estado e sociedade e, como consequência tentar compreender por que carecem de credibilidade perante os cidadãos. Face a essas circunstâncias, as questões que queremos examinar e tratar de responder neste trabalho são: quais são os fatores que podem explicar a crescente desconfiança e decepção 
em relação aos partidos políticos no Brasil? Este é um fenômeno estrutural ou conjuntural? Por que as pessoas não confiam nos partidos em uma época de consolidação poliárquica? É o capital social um dos caminhos que poderiam auxiliar a reverter esse processo?

Para responder a essas questões, estruturamos o trabalho em quatro partes: na primeira, contextualiza-se o papel dos partidos na teoria democrática contemporânea; na segunda parte, examinam-se os fatores histórico-estruturais que influenciaram a formatação e naturalização de normas, valores, atitudes e comportamentos em relação aos partidos políticos no Brasil; na terceira parte são analisados dados empíricos a respeito de como os cidadãos decodificam e desenvolvem suas representações cognitivas em relação aos partidos; e, finalmente, examinam-se as predisposições dos entrevistados sobre o desenvolvimento de capital social. Trata-se de estudo histórico-descritivo de comportamento político. As bases de dados utilizadas provêem de dados de pesquisas probabilísticas de opinião realizadas em dois contextos. O primeiro refere-se aos dados do ESEB-CAMPINAS e do LAPOP, para o Brasil, e o segundo banco de dados sobre capital social é do NUPESALUFRGS, para Porto Alegre.

\section{Situando os partidos brasileiros na construção democrática}

Nas últimas duas décadas o Brasil, à semelhança da maioria dos países da América Latina, ingressou num processo de restauração democrática com avanços significativos, particularmente na dimensão institucional. Todavia a expectativa gerada a respeito de uma relação mais madura, estável e eficiente entre Estado e sociedade via partidos políticos não tem se materializado. Desse modo, a democracia contemporânea, no que diz respeito a uma das suas instituições-chave de fomento democrático - os partidos parece ter entrado num processo de estagnação, agravado pelas percepções céticas e negativas dos cidadãos em relação a elas, especialmente em relação à sua capacidade e eficiência como mediadora política.

Apesar das tentativas de modernizar estas instituições, o intuito de valorizá-las perante os cidadãos, ganhando sua confiança, não tem ocorrido. De fato, os partidos são as instituições que apresentam os mais baixos níveis de confiança entre os brasileiros. Isto sugere que reformas institucionais per se não são suficientes para introduzir mudanças de caráter estrutural na dimensão cognitiva das pessoas a respeito dos partidos, é preciso ir além dessas iniciativas e pensar em alternativas para alcançar este objetivo. Quando o desafeto das pessoas em relação às instituições de mediação política é elevado, a situação tende a piorar se as condições econômicas também são precárias, produzindo um ambiente político instável. Desafeto político, neste artigo, é utilizado da mesma forma que Torcal (2003, p. 3) para quem é o "sentimento de impotência, cinismo e falta de confiança no processo político, nos políticos e nas instituições democráticas, porém sem questionar o regime político". 
Tais percepções, embora não ameacem a sobrevivência da democracia por retrocessos institucionais ou por golpes de Estado, constituem impedimentos de fomento a sua legitimidade, na medida em que as instituições centrais desse sistema político carecem, geralmente, de credibilidade perante os cidadãos. Igualmente, embora o Brasil tenha experimentado níveis razoáveis de crescimento econômico nos últimos cinco anos, ainda fica atrás de vários países da Região, e mesmo os avanços sociais não têm conseguido mudar radicalmente os níveis de pobreza e indigência, não justificando, portanto, a euforia que muitos analistas mostram em relação aos avanços sociais. De maneira geral, embora o país tenha diminuído os índices de pobreza, a desigualdade social, tem piorado de acordo com o coeficiente de Gini.

Nesse contexto, a insuficiência do processo democrático, particularmente no que diz respeito à resolução de problemas essenciais de natureza material, tem gerado descontentamento das pessoas com a situação social, materializado em atitudes e comportamento de desvalorização das instituições da democracia representativa, gerando um ambiente ao mesmo tempo poliarquicamente estável e socialmente instável.

Assim, constata-se, presentemente, segundo pesquisas de opinião pública realizadas na América Latina (como no Latinobarômetro, no World Values Survey, na Encuesta Panamericana, no LAPOP), desencanto e indiferença das pessoas em relação aos partidos políticos. Esse profundo malestar com essas instituições não é consequência de predisposições deliberadas de hostilidade por parte dos cidadãos em relação a essas instituições, mas derivam de uma relação de desconfiança construída historicamente na qual os partidos não são vistos como representantes autênticos das demandas da sociedade.

Neste sentido, os partidos políticos são permanentemente questionados em relação a uma das suas funções essenciais: a de canalizar ou intermediar os interesses e demandas da sociedade para transformá-los em estratégias políticas eficientes. Uma consequência imediata desta forma de ver os partidos é a erosão de sua credibilidade e legitimidade. Assim, o que se constata é uma ruptura crescente dos vínculos tradicionais entre os partidos e setores da sociedade civil. A construção de identidades coletivas, cada vez mais reduzidas no contexto da sociedade moderna, agrava a capacidade dos partidos, que já era reduzida, de representar interesses específicos num projeto unitário de sociedade.

Outro elemento que dificulta um eficiente funcionamento dos partidos no contexto do país se deve ao papel declinante das ideologias como fatores catalisadores de identidades coletivas. Nesse cenário, a política se torna imediatista e de reação, e não de ação estratégica. Para Lechner (1997), por exemplo, tal situação de ausência de códigos interpretativos que possibilitem estruturar suas crenças, deixa a sociedade órfã de símbolos interpretativos, reduzindo a potencialidade de representar correntes de opinião e crenças. 
Da mesma maneira, o crescente processo de individualização nas sociedades modernas, fruto do processo de globalização, dos problemas sociais e da falta de significado das instituições políticas na vida das pessoas contribui para que elas abandonem o mundo político, perdendo a confiança nessas instituições e nos gestores públicos. Complementa essa deserção dos cidadãos da vida pública e dos partidos a crescente corrupção política tanto de representantes eleitos quanto das instituições políticas. Tal situação é propícia para o surgimento de líderes neopopulistas que buscam uma aproximação direta com os cidadãos à margem dos partidos políticos. Drucker (1993, p. 118) é contundente ao afirmar que:

\begin{abstract}
Hoje em dia os partidos estão em farrapos em todas as partes. As ideologias que possibilitaram aos partidos europeus reunir facções diferentes em uma organização, para conquistar e controlar o poder perderam a maior parte de seu poder integrador. Os partidos e seus slogans não fazem sentido para os eleitores, especialmente os mais jovens.
\end{abstract}

Tal situação tem propiciado um campo para o surgimento de organizações sociais como canais alternativos de representação de interesses, na medida em que questionam o monopólio tradicional de representação dos partidos. Desse modo, tanto o neopopulismo, o aparecimento de novas formas de representação política, o declínio das ideologias como catalisadoras de identidades coletivas e a corrupção das organizações políticas contribuem para o enfraquecimento dos partidos políticos como instituições-chave da democracia representativa, produzindo uma relação de indiferença e antagonismo mútuo entre partidos e sociedade civil.

Nesse contexto, sem partidos eficientes, a democracia na sua dimensão representativa não prospera. Partidos eficientes são imperativos para a democracia porque processam as demandas da sociedade perante o Estado, trazendo, caso efetivos, estabilidade institucional e legitimidade societária. Partidos são também importantes na medida em que se constituem num dos principais pilares de fortalecimento democrático. De maneira geral, os partidos continuam a ser precários, ineficientes e, em muitos casos, recorrem a práticas atrasadas promovendo a corrupção. Assim, não se constituem em organizações capazes de empoderar nem formal nem emancipatoriamente a cidadania.

Com base nessas afirmações, pode-se dizer que o caminho da consolidação democrática, na dimensão dos partidos políticos no Brasil, temse mostrado mais difícil do que se previa quando o país entrou em processo de democratização. Ainda que se tenha institucionalizado uma democracia formal, persistem questionamentos sobre sua qualidade e governabilidade. A este respeito Mainwaring e Scully (2008) afirmam que, no caso da América Latina, torna-se necessário ir além dos conceitos de governabilidade e 
qualidade democrática e pensar numa governança democrática; ou seja, no caso dos partidos políticos, é imperativo que sejam eficientes na sua capacidade de mediação política, de educação política, de articular e agregar os interesses dos diferentes setores da sociedade, produzindo, desse modo, mais credibilidade e legitimidade aos olhos da cidadania. No entanto, o que tem ocorrido é o contrário: o desempenho dos partidos políticos não está à altura das expectativas que os cidadãos criaram por ocasião desse processo de revigoramento democrático.

Diante desta situação, no caso brasileiro se observa uma situação na qual, de maneira semelhante a outros países, a democracia em seu sentido difuso mostra um fortalecimento, mas ao mesmo tempo as instituições políticas, particularmente os partidos políticos, são consideradas instituições pouco confiáveis e, em alguns casos, inclusive, dispensáveis.

\section{O papel dos partidos nas novas democracias}

Há um consenso estabelecido, ao longo do tempo, a respeito das funções essenciais que um partido desempenha numa democracia. Tal ponto de vista se aprofundou e popularizou durante a chamada terceira onda da democracia (HUNTINGTON, 2000). De acordo com Mainwaring e Scully (2008), um sistema partidário institucionalizado apresenta quatro características: (1) promove padrões estáveis de competição partidária; (2) um número significativo de cidadãos desenvolve identidades partidárias estáveis; (3) os partidos assumem legitimidade como veículos para alcançar o poder; e (4) os partidos se solidificam, ou seja, não são meramente apêndices de líderes populistas.

Em relação ao primeiro ponto, não se pode negar que atualmente existe uma competição razoável e estável entre partidos no país. Já no que se refere ao segundo ponto, a identificação partidária geralmente é considerada baixa, se comparada com os chamados países desenvolvidos. No que diz respeito ao terceiro ponto, pesquisas têm mostrado, ao longo do tempo, que a confiança dos cidadãos nos partidos é baixa e, no caso brasileiro, ainda revelam traços personalistas e privatistas na sua estruturação da qual o quarto tópico se refere.

Nesse cenário, não é de surpreender que a ambivalência dos cidadãos em relação aos partidos é considerada um aspecto explicativo da baixa qualidade democrática (O'DONNELL, 2001). Para alguns autores tal situação é sintomática de uma crise de representação política (DOMINGUEZ, 1997; MAINWARING, BEJARANO e PIZARRO, 2006; BAQUERO, 2001), na qual as pessoas não demonstram interesse em assuntos políticos. De fato, uma das conclusões estabelecidas sobre o grau de capacidade cognitiva dos cidadãos é de que o cidadão médio está desinformado sobre as instituições políticas e processos, as condições socioeconômicas e atores políticos importantes, tais como gestores públicos e partidos políticos (FEREJOHN e SHIPAN, 1990). 
Nessas circunstâncias a probabilidade de surgirem democracias com pouca qualidade é elevada. O'Donnell (1991) identificou o que ele denominou de democracias delegativas, nas quais presidentes populistas alcançam o poder via eleições competitivas, porém, à margem dos canais partidários tradicionais, resultando, quando no poder, em comportamentos como donos pessoais da República e não como representantes políticos, colocando-se acima de qualquer sistema de controle e fiscalização. Desse modo, segundo o autor, democracias delegativas não são democracias consolidadas ou institucionalizadas, porém podem ser duradouras. Na maioria dos casos não se vislumbram ameaças eminentes de uma repressão autoritária aberta, mas tampouco se vislumbram avanços a uma responsabilidade institucionalizada.

Presentemente existem duas escolas de pensamento a respeito dos partidos políticos. Por um lado, há uma vertente que argumenta que os partidos estão em declínio e isso, portanto, constitui-se num grande problema que precisa ser resolvido. Uma segunda perspectiva sugere que ainda que os partidos tenham mudado drasticamente, eles têm se mantido fortes e influentes como no passado. Este segundo ponto de vista sugere que os partidos não estão em declínio, mas que simplesmente têm assumido novas formas de funcionamento para que se adaptem a um processo competitivo de mercado. Neste processo, o principal perdedor é o cidadão comum, posto que não dispõe de tempo para se informar, educar-se, confiar e se associar a partidos políticos existentes, por não haver estímulos para que as pessoas façam isso. Os partidos somente querem seu voto a cada quatro anos. Dessa forma, ainda que os partidos estejam perdendo o apoio tanto financeiro como pessoal de seus simpatizantes, isto não tem afetado sua capacidade para angariar recursos para campanhas eleitorais, selecionar e recrutar candidatos e debater políticas.

Nesse contexto, a partir da década de 1950, institucionalizou-se como axioma a idéia de que o progresso e desenvolvimento de um país passavam pela existência de organizações de mediação política, o que se convencionou chamar de democracia eleitoral (DYE, 2000), democracia minimalista (PRZEWORSKI et al, 2003) ou poliárquica (DAHL, 1971). Nessa dimensão de análise, os partidos políticos são considerados instituições-chave no funcionamento democrático, não apenas por serem canais de representação e de mediação entre os cidadãos e o Estado, mas por serem atores de intervenção na arena governamental decisória.

No caso brasileiro, de acordo com Wanderley Guilherme dos Santos (1987), os partidos monopolizam a função de representação política em virtude da consolidação de burocracias especializadas na arena democrática. O argumento de Santos sugere que o mero monopólio de representação, mesmo que democrático, não garante unanimidade de aceitação dessas organizações se elas não desempenham suas funções de forma eficiente, comprometendo o que Mainwaring chama de boa governança democrática.

Desse modo, o princípio de que basta ter instituições funcionando para fortalecer a democracia, no caso do Brasil está longe de ser uma 
unanimidade, se analisada em termos da eficiência da atividade mediadora que os partidos precisam desempenhar. No campo teórico, a dimensão estritamente procedimentalista tem enfrentado sérias críticas a respeito de seu caráter linear e causal. Exemplo de um campo que questiona tal teoria é o que propõe que as explicações de natureza cultural devem ser incorporadas para se ter uma compreensão mais profunda sobre a crise dos partidos em uma democracia representativa (ALMOND e VERBA, 1963; INGLEHART, 2002).

Atualmente, a Ciência Política continua preponderantemente a enfatizar que as instituições políticas, principalmente os partidos, são essenciais para o fortalecimento democrático. Se, por um lado, este posicionamento é quase unânime, por outro, não há um consenso sobre a qualidade e a influência que os partidos têm tido na promoção de uma cultura política mais democrática ou mais participativa.

De fato, na virada do milênio, constata-se que as organizações convencionais e tradicionais da democracia formal nunca tiveram avaliações tão baixas por parte dos cidadãos. Inclusive nos países mais desenvolvidos se atribui o surgimento de partidos populistas a uma desilusão com os partidos existentes. Entre os principais fatores desse desencanto está a percepção do aumento da corrupção, a qual é danosa para a construção democrática. No caso pontual do Brasil, pesquisa levada a cabo pelo Instituto Anti-Corrupción en América Latina (INEA, 2006) mostrou que, no período 2005-2006, o Brasil foi o único país que teve corrupção sistêmica estatal de alta nocividade social. As principais instituições colocadas em xeque pelo Instituto foram: 0 Legislativo, o governo central e, sobretudo, os partidos políticos. A alta nocividade social se manifesta nos elevados custos que estas práticas geram para o desenvolvimento do país, bem como seu impacto moral e social na vida social (INEA, 2006).

Para ilustrar este ponto, também é pertinente avaliar os dados produzidos pelo Relatório da Transparência Internacional sobre a corrupção no Mundo publicado em 2004. O que mais chama a atenção no referido Relatório é a percepção que as pessoas têm sobre os partidos políticos. Em 32 países, dos 62 estudados, os partidos políticos foram avaliados como as instituições mais afetadas pela corrupção. Igualmente os entrevistados dos 32 países responderam que, caso lhes fosse dada a oportunidade, limpariam a corrupção prioritariamente nos partidos políticos (TRANSPARENCY, 2004).

Neste sentido, pensamos que os partidos já não se constituem em uma corrente efetiva de transmissão entre sociedade civil e o Estado. As evidências acumuladas ao longo da história recente (Pesquisa Mundial de Valores, Latinobarômetro, Encuesta Panamericana, Pesquisas sobre Cultura Política na América Latina da Universidade de Vanderbilt, e investigações no Brasil), sinalizam para a existência de um abismo entre governantes e governados. Dessa maneira, os partidos detêm os maiores percentuais de rejeição e de desconfiança por parte da opinião pública, e são vistos como atores coletivos responsáveis, em boa parte, pela ingovernabilidade do país. 
Quando se contextualiza essa situação para o Brasil se verifica que o ranking dos partidos brasileiros está nas últimas posições em termos de legitimidade (LATINOBARÔMETRO, 1996-2005).

Um dos perigos da corrupção é de que produz escândalos políticos, e estes ajudam a gerar uma atitude de profunda desconfiança entre alguns setores da população, acarretando uma diminuição da participação. Nessa perspectiva, para Thompson (1995, p. 258-259) "uma sociedade na qual setores significativos da população têm abandonado o processo político, virando as costas para o sistema que eles julgam ser irremediavelmente corrupto, não é uma sociedade forte e vibrante".

Nessa perspectiva, não é inovador afirmar que o país atravessa uma época de marcada fragilidade institucional, aumento da corrupção e questionamento de práticas políticas tradicionais tais como o clientelismo, o personalismo e o patrimonialismo. Para Binetti e Carrillo (2004), por exemplo, a institucionalidade informal (clientelismo) que se estabelece nos países em desenvolvimento como o Brasil cria um obstáculo para a democracia. Como está bem documentado (HOLANDA, 1936; FAORO, 1958; NUNES, 1997), o clientelismo reside fundamentalmente na existência de uma cultura política patrimonialista da política e do poder, segundo a qual se concebe a política como a extensão do espaço privado, o que permite satisfazer os interesses particulares.

No sistema político brasileiro o clientelismo continua a orientar o comportamento dos partidos e serve como base de sua estabilidade, coesão e fortaleza. Soma-se a esses elementos uma prática recorrente de expulsão de mandatários no meio de seus mandatos. Nas décadas de 1980 a 2005, Argentina, Haiti, Brasil, Venezuela, Guatemala, Equador, Bolívia e Peru experimentaram este fenômeno. Se, por um lado, esse processo pode ser interpretado como um processo eficiente de fiscalização política e uma saudável modalidade de participação política da sociedade, por outro, parece ser um sintoma de um fenômeno antigo - a falta de credibilidade e legitimidade dos mandatários e das instituições políticas, pontualmente os partidos.

Assim, o problema não está na expulsão de políticos corruptos, mas coloca em evidência uma notória fragilidade do regime democrático e sua incapacidade de enfrentar as crises de representação político-econômicas. Dessa forma, o regime democrático tem sua estabilidade ameaçada pela situação social e uma moldura institucional que não consegue agregar o interesse e as necessidades da população.

Levando em conta a debilidade do desempenho partidário, é necessário considerar que toda e qualquer reforma institucional deve ter um caráter integral que inclua a sociedade como um todo e, fundamentalmente, está claro que não é suficiente mudar o desenho das instituições políticas, é imperativo transformar, também, a cultura política de uma sociedade, ou seja, seus valores, normas e crenças em relação à política. 
Uma crença que parece adquirir uma dimensão estrutural é o antipartidarismo que cresce na população brasileira, como atestam as investigações de opinião pública realizadas longitudinalmente. De maneira geral, o antipartidarismo pode ser conceituado como a atitude crítica aos partidos políticos e uma contestação à sua atuação no sistema político. Seguindo esta linha de raciocínio, Poguntke e Scarrow (1996) definem o antipartidarismo como um "desafeto em relação aos partidos, inclusive sua contestação" (p. 259). Para os autores existem várias formas de antipartidarismo: (1) contestação total dos partidos políticos fundamentada no princípio de que os partidos não são necessários para o funcionamento do sistema político democrático; (2) críticas aos partidos existentes, ou seja, ainda que se reconheça a importância de sua existência, questiona-se o seu comportamento; (3) o antipartidarismo cultural, que se refere a atitudes de cinismo em relação à utilidade dos partidos e dos políticos nos sistemas democráticos; e (4) o antipartidarismo reativo, que se refere às atitudes adotadas pelos cidadãos em resposta à sua insatisfação com 0 comportamento das elites políticas e dos partidos.

Pensamos que, no Brasil, prospera o antipartidarismo cultural na medida em que em vez de se buscarem soluções para fortalecer as instituições, buscam-se as pessoas e grupos, líderes ou lideranças, cujos atributos carismáticos são sempre proporcionais à sua capacidade de se impor sobre as instituições e deslegitimá-las ainda mais. Dessa maneira, perpetuase um ciclo vicioso, segundo o qual quanto maior é a deslegitimação institucional, mais se requer e, ao mesmo tempo, proliferam as lideranças que contribuem para neutralizar e desacreditar as instituições.

Tal situação é reforçada porque as instituições democráticas, em vez de exercer seus poderes legítimos de aplicar suas normatividades específicas e de funcionar democraticamente, serviram de suporte a poderes, grupos e setores que com maior eficácia e legitimidade reproduziram seu domínio e seu poder de enriquecimento. Assim, por trás do aparente consenso em relação à desejabilidade da democracia e dos partidos políticos para o bom funcionamento das democracias contemporâneas, persistem divergências significativas, sobretudo a respeito do desempenho dos partidos existentes.

A decepção com os partidos está fundamentada no desempenho deficiente em tarefas básicas, tais como a educação política e a constituição de cidadãos mais protagônicos e conscientes nesse sistema político. Tanto isso é fato que se tem produzido uma grande variedade de trabalhos sobre o declínio dos partidos políticos e levantado dúvidas sobre seu papel e futuro na democracia moderna (BAQUERO, 2001; LAWSON e MERKL, 1988). Por exemplo, argumenta-se que os partidos estariam perdendo sua capacidade de representação como instrumentos de mobilização e como canais de articulação e agregação. No entanto, continuam a ter o monopólio do recrutamento político e da organização do Congresso e do governo. Neste sentido, ainda que suas funções representativas tenham diminuído, seu papel institucional se mantém intacto. 
Isso não significa que o sistema partidário tenha conseguido se adaptar às novas demandas de uma sociedade em constante transformação. De fato, quando os partidos não conseguem desempenhar sua função essencial - a de representar - deixa de existir uma comunicação eficiente entre os atores envolvidos no processo de construção democrática. A tendência nessas circunstâncias é a institucionalização de práticas oligárquicas. O resultado acaba redundando na permanente desproteção da maioria e na proteção dos poderosos e influentes no sistema político. Tal situação tem levado ao surgimento de massas desmobilizadas que se convertem ao partido dos não eleitos (VALELLY, 2002). É evidente que esses eleitores possuem uma influência mínima ou nenhuma no sistema político.

Dessa maneira, paradoxalmente, ao mesmo tempo em que os partidos são vistos como veículos essenciais da democracia representativa, também são considerados incapazes de desempenhar as funções que são fundamentais para o fortalecimento democrático (SÁNCHEZ-PARGA, 2001; DI TELLA, 1998). Observa-se, portanto, que os partidos políticos que tradicionalmente eram considerados organismos de catalisação da participação política e mediadores entre o Estado e sociedade, estão sendo confrontados pelo rápido declínio da identificação partidária. Essa tendência antiparticipativa contribui para debilitar a legitimidade dos partidos como unidades de mediação política e de representação.

\section{Elementos histórico-estruturais do Brasil}

Uma análise retrospectiva da história do Brasil mostra uma tendência permanente de escândalos políticos. Está além dos objetivos deste artigo fazer um levantamento de todas as ocorrências, embora seja possível identificar na última década (2001-2010) alegações de corrupção na compra de votos pelos partidos no poder, a prevalência de serviços públicos deficientes, o crescimento da violência e a expansão da pobreza e da exclusão social. Essas ocorrências dentro de um contexto de democratização geraram perplexidade, pois "poucos esperavam que a fragmentação política e o subdesenvolvimento institucional se tornariam desafios" de uma crise permanente de governabilidade (AMES e POWER, 2007, p. 1).

No que se refere à dimensão de fragmentação política, Payne et al (2002) ressaltam o elevado índice de fragmentação partidária do país, sendo que o número efetivo médio de partidos no Brasil (6.70), é o dobro da média de outros países. Na mesma linha de pensamento, o Brasil é caracterizado como uma nação pouco institucionalizada em temos de partidos políticos (MAINWARING e SCULLY, 1995). Em estudo desenvolvido por Ames e Power (2007), o sistema partidário é descrito como sendo altamente fragmentado, competitivo, volátil e com uma institucionalização frágil.

A fragmentação da sociedade brasileira é reflexo dos enraizamentos históricos e culturais de práticas clientelistas e corporativas, que têm impedido a coesão desejada. A inoperância dos partidos tradicionais tem 
permitido que o clientelismo, o personalismo e o patrimonialismo continuem sendo elementos articuladores preponderantes na política do Brasil.

Um dos primeiros autores que tratou de caracterizar a cultura política brasileira foi Sérgio Buarque de Holanda (1936), para quem o Brasil é herdeiro de uma nação ibérica e de uma cultura personalista, onde os vínculos pessoais têm sido decisivos nas relações sociais e políticas. Em tal cenário, o desafio dos intelectuais da época era saber como incidir em transformações profundas em um país no qual eram mantidos os fundamentos tradicionais da situação que se queria superar (HOLANDA, 1936). Seria necessário transformar as relações políticas que insistiam em manter traços arcaicos herdados da colonização portuguesa e do império. O conceito utilizado por Holanda para descrever a preocupação das elites em manter uma aparente harmonia e de sua capacidade de reagir com violência quando os acordos informais não funcionavam, era a cordialidade. Esse conceito, por um lado, mostra o pacifismo, a hospitalidade e a generosidade do homem brasileiro e, por outro lado, mostra a ausência de um ordenamento impessoal que caracteriza o Estado burocrático e que funciona como elemento estruturador de uma cultura política clientelista.

$\mathrm{Na}$ década de 1950, Raymundo Faoro (1958) sugeria que era o patrimonialismo o principal eixo da cultura política brasileira. O sistema patrimonial coloca os cidadãos em uma rede patriarcal na qual eles representam a extensão da casa do soberano. Para Faoro, esta estrutura política e social havia permanecido na política brasileira até a época do Estado Novo.

O patrimonialismo se caracteriza pela utilização da propriedade pública para fins privados, onde ocorre uma indistinção total entre o Estado patrimonial e a família patriarcal. Para Weber, em seu livro Economia e Sociedade (2004), o patrimonialismo se refere a formas de governo que são baseadas na matriz da casa-família de quem manda. Desta forma, a autoridade do governante é patronal-familiar, e a mecânica da casa é o modelo de administração política. A dominação patrimonial é um caso especial de dominação patriarcal que contrasta com o modelo ideal de Weber de burocracia racional-legal, a qual é comandada por atores impessoais e substituíveis. Contudo, no atual contexto se fala de um patrimonialismo ou neopatrimonialismo quando, apesar da existência de procedimentos poliárquicos, continuam a se implementar políticas que dão privilégios às minorias influentes, concedendo-se imunidade a quem atua em desacordo com a lei, e se institucionaliza uma política que se materializa no ditado é dando que se recebe.

A existência de estruturas oligárquicas e de personalização do poder, o mandonismo e a falsificação do voto e a desorganização dos serviços públicos locais são características desse tipo de sistema. As estruturas partidárias da época faziam favores pessoais de toda ordem, desde conseguir emprego, até escrever cartas ou recibos, ao mesmo tempo levavam os eleitores para votarem em seus candidatos (voto de cabresto), em troca, o governo estatal 
disponibilizava dinheiro, empregos e favores em geral aos coronéis.

Em tais circunstâncias, o clientelismo surge como decorrência do coronelismo. Este fenômeno é mais amplo e atravessa toda a história política do país. É um tipo de relação que envolve a concessão de benefícios públicos entre os atores políticos. Na vigência do coronelismo o controle do cargo público era visto como importante instrumento de dominação e não como simples empreguismo. O emprego público irá adquirir importância como fonte de salário nas relações clientelísticas (CARVALHO, 1987, 1997 e 2000). Desta forma, para Souza (1976), o clientelismo não se constitui necessariamente numa característica da política brasileira ou como uma etapa de desenvolvimento, mas sim como um instrumento de controle de recursos políticos e de sua utilização pelos partidos políticos, buscando, dessa forma, não somente o poder para eles, mas o reconhecimento de seu poder pela população enquanto instituições legítimas de mediação política.

Sobre o mesmo tema, Roberto DaMatta (1993) argumenta que no Brasil o espaço da casa se reproduz e se instrumentaliza dentro dos espaços públicos, propiciando com que alguns elementos autoritários fiquem tão arraigados dentro da cultura política que, muitas vezes, não são vistos como assuntos políticos importantes. A naturalização desses elementos, de acordo com DaMatta, está relacionada a problemas culturais e históricos profundos, entre os quais o autor destaca quatro: (1) no Brasil, a persistência do clientelismo e do personalismo tem raízes profundas; (2) a força do familismo e do espaço social da casa é diretamente proporcional à ausência da confiança na vida pública; (3) as relações têm muito mais peso e importância do que as leis e as normas; e (4) as tradições jurídica e política são altamente centralizadoras. Esse quadro favorece a continuidade de uma situação perversa do ponto de vista da cultura política democrática.

Nessa mesma linha de raciocínio, Reis (1995 e 1998) considera aplicável ao caso brasileiro o conceito de familismo amoral de Banfield, o qual corresponde a um ethos da lógica familista privada, a qual exclui qualquer tipo de solidariedade fora do círculo familiar. De acordo com a autora

\begin{abstract}
a situação retratada por Banfield sugere que a falta de confiança generalizada leva os membros de uma comunidade a considerar regressar para a esfera privada como seu domínio mais racional. A existência desta característica propicia que em sociedades como a brasileira existam dificuldades para estabelecer a confiança interpessoal e a solidariedade social na medida em que disparidades agudas nas experiências de vida geram diferenças tão grandes nas orientações cognitivas que sentimentos de pertencer a uma comunidade simplesmente não conseguem se institucionalizar (REIS, 1998, p. 121).
\end{abstract}

Em análises mais recentes da política brasileira, Edson Nunes (1997) 
postula a existência de quatro gramáticas políticas que caracterizam este país ao longo da história: o clientelismo, o corporativismo, 0 insulamento burocrático e 0 universalismo de procedimentos. $O$ clientelismo e 0 corporativismo constituem uma gramática personalista, com base nas relações pessoais com padrões institucionalizados de poder político. As relações pessoais e hierárquicas foram cruciais para a obtenção de favores políticos, transformando as instituições do Estado em mecanismos ou instrumentos de troca de favores.

Com a institucionalização da racionalidade burocrática e de normas com base em relações impessoais, o universalismo de procedimentos e 0 insulamento burocrático acabam funcionando como medidas de proteção contra o abuso do poder do Estado e se apresentam como gramáticas políticas alternativas ao clientelismo. Não é por acaso que neste contexto o personalismo impregnou as redes de relações sociais e as instituições políticas contemporâneas; mas como essas relações são tratadas como elementos informais e fluidos, são, de maneira geral, ignorados por cientistas políticos.

O clientelismo político moderno foi constatado em certos centros urbanos como São Paulo com o malufismo, e no Rio de Janeiro com o chaguismo. Segundo Eli Diniz (1982), as práticas clientelistas evoluíram inseridas em uma organização complexa, a máquina chaguista, articulando várias redes de clientelas estruturadas em volta de políticos com muita experiência em suas respectivas áreas de atuação. Tal situação é corroborada por Avelino Filho (1991), para quem a grave situação social contemporânea tem sido amenizada pelos programas sociais paternalistas e compensatórios, os quais têm contribuído para o círculo vicioso do sistema político - sociedade desigual e práticas clientelistas. Ao mesmo tempo, outro elemento que contribui para manter uma cultura política clientelista no Brasil diz respeito ao sistema eleitoral de representação proporcional com listas abertas, que contribui para que o eleitor se centre muito mais no candidato do que no partido. A consequência é que uma vez eleitos, os políticos não são fiscalizados eficientemente pelos partidos e, dessa forma, detêm ampla autonomia para trocar de partido com muita facilidade (SAMUELS, 1997).

Nesse contexto, as dimensões histórico-estruturais como o patrimonialismo, o clientelismo, o familismo e o personalismo geram uma assimetria temporal na qual não há uma compatibilidade entre a democracia e as atitudes dos cidadãos, que se orientam muito mais por motivações subjetivas e emocionais. Situações como esta possibilitam o surgimento, no atual contexto, daquilo que tem sido denominado de teoria do desgoverno (SÁNCHEZ-PARGA, 2001, p. 21) na qual a governabilidade serve apenas para tornar "governável o desgoverno", fruto das políticas públicas assistencialistas e que incidem diretamente em três dimensões: (1) na exclusão e no empobrecimento de vastos setores da população; (2) na corrupção institucional; e (3) na violência.

Em síntese, a existência de um sistema partidário frágil no Brasil é atribuída, por grande parte da literatura sobre a democracia, ao 
corporativismo, ao clientelismo, à estrutura centralizada do Estado, à oligarquização do jogo político, à ausência da participação política e à falta de uma legitimidade político-partidária no processo de construção democrática. A este respeito, Mainwaring (2001) sugere que a baixa institucionalização do sistema partidário brasileiro deriva do clientelismo, do patrimonialismo, da corrupção e do nepotismo que acabam transformando as políticas sociais em interesses particulares e, consequentemente, minando a estabilidade política e econômica.

A análise destes autores serve para mostrar que a evolução do sistema político brasileiro e as formas como as instituições se estabelecem têm contribuído para a manutenção de traços tradicionais da política que atuam em detrimento do estabelecimento de uma base sólida sobre a qual uma democracia socialmente eficiente possa ser construída.

A fragmentação e atomização da sociedade civil, características da política no Brasil, também têm problemas que limitam severamente a democratização. Neste sentido, somos favoráveis à incorporação na análise dos partidos políticos, dos fatores históricos que têm se cristalizado e que impedem o fortalecimento democrático (no plano das instituições e da cultura). Tanto a evidência histórica como empírica sugerem que o clientelismo, o personalismo e o patrimonialismo têm plantado raízes profundas nos processos de desenvolvimento partidário. Desse modo, o regime político no Brasil é democrático, mas não consegue promover a construção de partidos fortes, nem diminuir a influência de uma política personalista.

É neste tipo de cenário que assume relevância o estudo de como os brasileiros têm internalizado normas, valores e crenças sobre a política, por meio de investigações empírico-quantitativas que têm proliferado nos últimos anos.

\section{A dimensão empírica}

Frente aos fatores acima mencionados, uma das principais dimensões para avaliar como as pessoas percebem os partidos políticos diz respeito ao seu desempenho como entidades de mediação política entre Estado e sociedade. A literatura examinada sinaliza para uma percepção preponderantemente negativa. Quando solicitamos aos entrevistados que fizessem uma avaliação dos partidos, as respostas para 2002 e 2006, são parecidas, conforme mostra a Tabela 1. 
Tabela 1 - Avaliação da atuação dos partidos políticos (\%)

\begin{tabular}{ccc}
\hline & $\mathbf{2 0 0 2}$ & $\mathbf{2 0 0 6}$ \\
\hline Péssima & 19,6 & 19,2 \\
Ruim & 37,2 & 40,2 \\
Regular para ruim & 3,3 & 4,8 \\
Regular para bom & 4,6 & 9,3 \\
Boa & 31,1 & 24,7 \\
Ótima & 4,2 & 1,8 \\
\hline Total de entrevistados & 2335 & 972
\end{tabular}

Fonte: ESEB (2002 e 2006).

A Tabela 1 mostra um padrão avaliativo semelhante para os dois períodos examinados. Tanto nas eleições presidenciais de 2002 quanto nas de 2006, para a maioria dos brasileiros, se somadas as três primeiras categorias (péssima, ruim e regular para ruim) a média para os dois anos é de $62,1 \%$. Contextualizando esses dados ao contexto histórico e atual da democracia brasileira, a média é elevada per se, constituindo-se, no nosso entender num constrangimento significativo de desinstitucionalização partidária.

O desafeto das pessoas pelos partidos políticos fica ainda mais evidente quando se examina a grau de vinculação deles com essas instituições. Pressupõe-se que o treinamento cívico gradual advindo de práticas participativas longitudinais fortaleça a construção de identidades coletivas secundárias, ou seja, via partidos políticos. Esperar-se-ia que, de uma eleição para outra, os eleitores mantivessem suas convicções partidárias. Assim, foi solicitado aos entrevistados que se posicionassem em relação a identificar algum partido que em sua opinião representasse sua maneira de pensar. Os dados estão na Tabela 2.

Tabela 2 - Algum partido político representa a sua maneira de pensar? (\%)

\begin{tabular}{cccc}
\hline & $\mathbf{2 0 0 2}$ & $\mathbf{2 0 0 6}$ & $\mathbf{2 0 0 7}$ \\
\hline Sim & 40,7 & 29,4 & 32,0 \\
Não & 59,3 & 70,6 & 68,0 \\
\hline Total de entrevistados & 2387 & 950 & 1161 \\
\hline
\end{tabular}

Fonte: ESEB (2002 e 2006); LAPOP (2007).

Os dados da Tabela 2 são eloquentes do desafeto dos brasileiros em relação aos partidos. De 2002 para 2006, o índice de pessoas que consideraram não ter pontos de convergência com os partidos aumentou mais de $10 \%$ e em 2007, ano não eleitoral, a média se manteve. Estes dados revelam que os partidos não se constituem em pontos de referência para a construção de identidades coletivas políticas estáveis. Desse modo, sem uma estrutura partidária intermediária institucionalizada, os eleitores, de maneira geral, recorrem a formas privadas de resolução de conflitos. Na medida em 
que as massas estão destituídas de um poder político eficiente, elas estão vulneráveis a apelos demagógicos e populistas. Sem uma estrutura mediadora eficiente, o sistema político tende a se tornar inerentemente instável, pois os partidos têm seguidores conjunturais e pouco estruturados ideologicamente. Em tal contexto, os representantes eleitos não sabem exatamente a quem ou que interesses representam, os partidos são dominados e controlados por personalidades políticas e o eleitor não tem controle sobre quem votou, pois na maioria dos casos não lembra em quem votou.

Igualmente, quando a fragilidade do sistema partidário é elevada, como é o caso do sistema brasileiro, a instabilidade societária é a regra, embora conviva com uma estabilidade jurídica formal. Essa assimetria surge em virtude da impossibilidade de construir uma tradição partidária longitudinal, estabelecendo uma diferença entre a instituição e seus ocupantes eventuais. Se tal separação não se materializa, o resultado é o personalismo na vida partidária do país. A consequência, nesse cenário, não pode ser outra senão o desgosto pelos partidos, como se observa na Tabela 3.

Tabela 3 - Gosta de algum partido político? (\%)

\begin{tabular}{ccc}
\hline & $\mathbf{2 0 0 2}$ & $\mathbf{2 0 0 6}$ \\
\hline Não & 51,2 & 65,9 \\
Sim & 48,8 & 34,1 \\
\hline Total de entrevistados & 2466 & 972 \\
\hline \multicolumn{2}{c}{}
\end{tabular}

Em face do cenário histórico de práticas partidárias deletérias para a construção de uma cidadania ativa e participativa, não é surpresa constatar que a maioria dos brasileiros não simpatiza com partidos políticos. Nem mesmo o chamado treinamento cívico eleitoral, ou seja, a experiência com eleições por meio do voto parece ter sensibilizado os cidadãos sobre a importância de ter partidos fortes e eficientes. Desse modo, o desenvolvimento de organizações que funcionam como mediadores entre Estado e sociedade à margem das organizações partidárias tem experimentado um crescimento significativo. A questão que surge é: essas práticas são majoritariamente utilizadas pelas pessoas ou ainda estão em um estágio incipiente de organização política? É este o tema que tratamos a seguir.

\section{O papel do capital social}

No passado, quando a moldura institucional de representação política era ineficiente, 0 resultado desembocava geralmente em rupturas institucionais ou golpes de Estado, pois os canais de expressão dos interesses societários não funcionavam e estavam envolvidos em atividades de 
corrupção política. Tal situação de crise institucional, dificilmente (embora não impossível) poderia ocorrer nos dias de hoje, na medida em que não existem predisposições nem, por exemplo, das forças armadas nem da população para empreender uma aventura desse tipo. O que se observa na sociedade contemporânea é um redirecionamento dos cidadãos que não acreditam nas formas convencionais de representação política para modalidades ou canais à margem das instituições ortodoxas, sendo elas associações voluntárias e organizações da sociedade civil. Tal redirecionamento na Ciência Política tem se denominado de capital social.

O capital social (CS) tem como meta o benefício de potencializar a ação coletiva por meio da integração das pessoas de maneira eficiente. As metas podem ser econômicas (obtenção de lucros, compartilhamento de informação sobre produtos, e conseguir emprego); intermediárias (meios para alcançar determinados fins, tais como acesso a mercados); e não econômicas (seguridade, credibilidade, legitimidade, coesão e aceitação sociais). O que deve ser enfatizado é que, embora o CS possa ter o efeito previsto em alcançar a ação coletiva, em alguns casos tais metas podem ser frustradas e o resultado ser negativo.

A emergência de modalidades alternativas, preponderantemente comunitárias de associação política, tem chamado a atenção da Ciência Política pelo amplo descrédito que os partidos possuem perante a população e as consequências que podem vir para a própria democracia. Um dos resultados mais visíveis tem sido o resgate do interesse pelas associações voluntárias e a confiança social influenciada pelas teorias de CS (PUTNAM, 2000).

Para a perspectiva do CS, o declínio dos partidos pode ser considerado como parte de um desenvolvimento mais amplo que afeta as agências tradicionais utilizadas para a ação política (NORRIS, 2001), associada à falta de tempo dos cidadãos para se dedicarem mais aos assuntos de natureza política e, muito menos, para se envolverem em ações políticas. As pessoas estariam preferindo formas mais diretas e comunitárias de associação política para resolverem problemas imediatos. Se os novos movimentos sociais têm se constituído em formas alternativas de mobilização política, protestos e canais de expressão alternativa para os cidadãos, a questão que surge é: como ficam os partidos neste contexto?

Cremos que atualmente os movimentos informais de mobilização política vieram para ficar. Isso, no entanto, não significa que as agências convencionais de participação e de mediação política tenham que ser substituídas. Na realidade o que tem ocorrido é a ampliação de opções de atividades disponíveis para os cidadãos, em virtude da ineficiência das organizações tradicionais de mediação política. Desta maneira, é mais útil dividir essas atividades entre ações orientadas pelos cidadãos que se relacionam com os partidos e o processo eleitoral; e as que se orientam pela defesa de temas específicos, tais como a defesa do consumidor, organização de abaixo-assinados, protestos e demonstrações catalisadas por grupos 
comunitários com o objetivo de alcançar metas específicas. Nesta perspectiva, requere-se um novo tipo de relacionamento entre o representante eleito com o cidadão com base na cooperação recíproca e não na dependência de uma política imposta de cima para baixo.

A diferença para as modalidades anteriores é que se coloca o relacionamento entre eleitores e representantes em um novo patamar, no qual a demagogia e práticas clientelistas são controladas e possivelmente eliminadas. Não há garantia, obviamente, que este será sempre o caso, pois evidências de investigações sobre esta temática sugerem que, em muitos casos, mesmo com a participação comunitária, os resultados podem fortalecer práticas que visavam eliminar. Independentemente dos resultados, o que não se pode negar é que a ação coletiva por meio de demonstrações e protestos tem sido aceita como mecanismo socialmente aceitável de externar demandas e reivindicações.

Iniciativas de mobilização política que se orientam a causas específicas têm como objetivo pressionar o Estado a dar respostas mais rápidas para problemas comunitários. Tal rapidez nem sempre é alcançada pelos partidos. Elas buscam, por exemplo, alterar padrões sistemáticos de comportamento social, proporcionando novas alternativas de organização comunitária com objetivos políticos à margem dos partidos. Essa forma alternativa de organização comunitária tem sido considerada na Argentina um espaço de reconciliação subjetiva, materializada em uma prática concreta de democracia direta e ação coletiva, alterando o significado da política e da democracia. O slogan que se popularizou e é um reflexo do sentimento dos cidadãos em relação à política e às instituições políticas é que se vayan todos (que todo mundo vá embora).

Apesar da aparente efervescência de formas alternativas de participação política e de modalidades de construção de identidades coletivas à margem das instituições convencionais, e que se refletem na existência de inúmeras ações coletivas autônomas e comprometidas com o público, não se pode concluir que exista uma sociedade civil forte que corresponda às exigências de uma democracia institucionalizada. Para avaliar esta questão, utilizam-se dados de pesquisa de opinião realizada em Porto Alegre-Brasil, pois não se localizaram questões desta natureza em nível nacional. Acreditase, no entanto, que os resultados de Porto Alegre podem gerar subsídios importantes para a compreensão do fenômeno associativo comunitário no resto do país.

$\mathrm{Na}$ Tabela 4, examinam-se as predisposições dos entrevistados em relação a sua participação individual e a opinião deles sobre como o governo (nos seus diferentes níveis) trata os cidadãos. 
Tabela 4 - Importância da participação e opinião sobre a participação (\%)

\begin{tabular}{ccc}
\hline & $\begin{array}{c}\text { O(a) Sr(a) considera importante a } \\
\text { sua participação na política para } \\
\text { resolver os problemas do país? }\end{array}$ & $\begin{array}{c}\text { Para o(a) Sr(a), a } \\
\text { opinião da maioria das } \\
\text { pessoas é levada em } \\
\text { conta no país? }\end{array}$ \\
\hline Sim & 73 & 19 \\
Não & 26 & 79 \\
NS/NR & 01 & 02 \\
\hline Total de & 510 & 510 \\
entrevistados & Fonte: NUPESAL (2005)
\end{tabular}

Fonte: NUPESAL (2005).

Como se pode observar na primeira coluna da Tabela 4, 73\% dos entrevistados responderam ser fundamental a participação das pessoas na política, mas, ao mesmo tempo, verifica-se que somente $19 \%$ dos portoalegrenses consideram que a opinião das pessoas é levada em conta no país. Tais dados sugerem, consistentemente com os dados anteriores, que a imagem dos partidos é negativa.

Ao se examinar se as pessoas se envolvem em atividades que requerem uma predisposição coletiva, as respostas sugerem a ausência de estoques de capital social na dimensão pessoal, o que, como já argumentamos, pode se transferir para a dimensão política, gerando uma descrença generalizada nas instituições políticas, especialmente nos partidos.

Tabela 5 - Nos últimos 4 anos, você resolveu algum problema de forma coletiva? Qual? (\%)

\begin{tabular}{lcc}
\hline & $\mathbf{2 0 0 0}$ & $\mathbf{2 0 0 5}$ \\
\hline Unem-se na busca de infraestrutura comunitária & 5 & 3 \\
Unem-se em movimentos políticos & 2 & 1 \\
Unem-se na busca de políticas públicas por parte do Estado & 4 & 3 \\
Unem-se em movimentos corporativos de classe & 1 & 1 \\
Unem-se em função de campanhas sociais & 2 & 1 \\
Outras motivações (ajuda, emprego, conhecidos) & 3 & 2 \\
Capital social individual (focado em seus interesses) & 1 & 1 \\
Não se envolvem em nenhuma atividade & 82 & 87 \\
\hline Total de entrevistados & 460 & 510 \\
\hline
\end{tabular}

Fonte: NUPESAL (2000 e 2005).

Os dados mostram que além dos cidadãos não participarem de atividades convencionais da política (partidos), eles não mostram comportamentos participativos em atividades não convencionais ou associativas. Assim, embora a construção de capital social pudesse ser valiosa para resgatar a credibilidade dos partidos, na medida em que a participação cresce no âmbito comunitário e se proporcionam oportunidades para uma 
participação direta, tal prática incidiria na predisposição dos cidadãos, no sentido pedagógico, de valorizar os partidos.

\section{Considerações finais}

O objetivo deste artigo foi tentar compreender por que os brasileiros não confiam nos partidos políticos. Ao analisar os vários aspectos que possibilitam uma maior compreensão desse fenômeno, chega-se à conclusão de que falar da revalorização dos partidos políticos ou da necessidade de centralizar as práticas políticas na forma partido nas últimas décadas pode parecer um contrassenso, na medida em que as orientações dos cidadãos nos últimos tempos são de uma opinião pública manifestamente hostil às formas partidárias de participação. O papel hegemônico dos partidos e sistemas de partidos no processo de construção da cidadania encontra cada vez maiores resistências no espaço de uma sociedade civil desmobilizada (JIMENEZ, 2008).

Igualmente, um aspecto essencial no processo de fortalecimento democrático vai além da ação voluntarista da sociedade civil ou de associações secundárias, abarcando também as transformações das instituições do Estado, neste caso, os partidos políticos. No entanto, o estabelecimento de uma sinergia entre a dimensão formal e informal de representação política está além do atual estágio de desenvolvimento democrático. Isto não implica, entretanto, que não se deva ir além da abordagem formal da política e combinar reforma democrática na política com a democratização substantiva em outras esferas.

Um fato incontestável na virada do século $X X$ é que a maior inovação política moderna - a democracia representativa - exige instituições intermediárias para conectar Estado e sociedade, ou seja, partidos. Para que a democracia se legitime de forma plena, é imperativo que os cidadãos se conectem ou se identifiquem com os partidos, pois isso possibilitaria a constituição da estabilidade política e societária com controle efetivo dos eventuais e normais conflitos que surgem. No entanto, o colapso do engajamento das pessoas com os partidos é um dos fenômenos mais importantes dos últimos anos. A hostilidade das pessoas em relação aos partidos é uma evidência perturbadora do afastamento e indiferença da cidadania em relação à política, o que poderá acarretar a manutenção de vícios políticos tradicionais e atrasados que comprometem a solidificação da democracia no país.

Assim, segundo Martins (2002), embora se observem avanços significativos na dimensão procedimental da política, frutos da lógica capitalista e da globalização, traços antigos tais como o patrimonialismo e a representação hierárquica, foram preservados pelas elites dos países em desenvolvimento na modernização de suas instituições públicas e privadas.

O resultado dessas circunstâncias é uma sociedade de massas que convive simultaneamente com avanços formais e atrasos em termos de 
predisposições atitudinais e comportamentais que inibem a constituição de uma base normativa de apoio às instituições políticas. Este é o caso dos partidos que se mostram frágeis, da cidadania que está longe de ser considerada qualificada, das atitudes políticas que tendem a desvalorizar os princípios democráticos, do comportamento político imediatista e guiado por razões instrumentais e não por princípios ideológico-partidários e dos partidos que não são representativos da população.

Uma democracia com essas características, contrariamente às chamadas democracias consolidadas, mostra uma tendência a reproduzir vícios do passado. Fomentam, portanto, práticas políticas que minam a solidez democrática, propiciando o surgimento de outros adjetivos (democracia iliberal, democracia defeituosa e democracia eleitoral, entre outros) que meramente mascaram uma realidade incontestável. Ou se reinventam os partidos para serem intermediários eficientes e eficazes da cidadania ou estamos propensos a viver numa democracia inercial. Em tal democracia, há avanços formais e de procedimentos simultaneamente com a estagnação de investimentos sociais aliados a uma crescente descrença nas instituições políticas, entre as quais figura como entidade central o partido político.

Em síntese, um sistema de partidos consolidado incide no fortalecimento democrático de um sistema político por três caminhos: (1) horizontaliza a representação política; (2) produz legitimidade que propicia estabilidade ao sistema; e (3) facilita a governabilidade. Por sua vez, o capital social possibilita que novas formas de sociabilidade e cooperação se materializem na comunidade. O principal ganho é que a sociedade coletiva se experimenta por meio da participação em organizações e mediante sua representação no espaço público. Daí que o desafio é encontrar caminhos que propiciem um resgate da confiança nos partidos políticos, fortalecendo ao mesmo tempo o capital social. É este, em nossa opinião, o principal desafio democrático do Brasil no presente e no futuro.

Marcelo Baquero é professor no Programa de Pós-Graduação em Ciência Política da UFRGS, Doutor em Ciência Política (Florida International University). Possui pós-doutorado em Ciência Política pelo Instituto Gino Germani (UBA) e pela Universidade de Sussex. É coordenador do Núcleo de Pesquisa sobre a América Latina (UFRGS).

E-mail: nupesal@yahoo.com.br

Bianca de Freitas Linhares é Doutora e Mestre em Ciência Política (UFRGS), Bacharel e Licenciada em Ciência Política (UFRGS), pesquisadora do Núcleo de Pesquisa sobre a América Latina (UFRGS).

E-mail: bipolitica@hotmail.com 


\section{Referências:}

ALMOND, Gabriel; VERBA Sidney. The civic culture: political attitudes and democracy in five nations. Princeton: Princeton University Press, 1963.

AMES, Barry; POWER, Timothy. Parties and governability in Brazil. In: WEBB, Paul; STENSFIELD, David (Eds.). Political parties in transitional democracies. Oxford: Oxford University Press, 2007. p. 179-213.

AVELINO FILHO, George. Política e políticas sociais no Brasil: um estudo sobre a Previdência. 1991. 116 f. Dissertação (Mestrado em Sociologia) - Faculdade de Filosofia, Letras e Ciências Humanas, Universidade de São Paulo [1991].

BAQUERO, Marcello. A vulnerabilidade dos partidos políticos e a crise da democracia na América Latina. Porto Alegre: Editora da UFRGS, 2001.

BINETTI, Carlos; CARRILLO, Fernando. Democracia con desigualdad? Una mirada de Europa hacia América Latina. Bogotá: BID/IGG Institut, 2004.

CARVALHO, José M. de. Os bestializados. O Rio de Janeiro e República que não foi. São Paulo: Cia das Letras, 1987.

Mandonismo, coronelismo, clientelismo. Dados, Rio de Janeiro, v. 40, n. 2, p. 229-250, 1997.

Rui Barbosa e a Razão Clientelista. Dados, Rio de Janeiro, v. 43, n. 1, p. $83-117,2000$.

DAHL, Robert. Poliarchy: participation and opposition. New Haven: The Yale University Press, 1971.

DAMATTA, Roberto. Reflexões sobre o público e o privado no Brasil. Caderno de Ciências Sociais, Belo Horizonte, v. 83, n. 3, p. 51-62, abr. 1993.

DINIZ, Eli. Voto e máquina política: patronagem e clientelismo no Rio de Janeiro. Rio de Janeiro: Paz e Terra, 1982.

DI TELLA, Torcuato. Crisis de representatividad y sistema de partidos políticos. Buenos Aires: Nuevohacer, 1998.

DOMINGUEZ, Jorge. Latin America's crisis of representation. Foreign Affairs, Tampa, v. 76, n. 1, jan.-fev. 1997.

DRUCKER, Peter. Sociedade pós-capitalista. São Paulo: Pioneira, 1993. 
DYE, Thomas. Politics in America. New York: Prentice Hall, 2000.

ESEB. Estudo eleitoral brasileiro 2002: CESOP-FGV/BRASIL02.DEZ-01838. In: Banco de Dados do Centro de Estudos de Opinião Pública - CESOP-UNICAMP. 2002. Disponível em:

<http://www.cesop.unicamp.br/site/htm/busca/php>. Acesso em: 14 abr. 2009.

. Estudo eleitoral brasileiro 2006: CESOP-IPSOS/BRASIL06.DEZ02489. In: Banco de Dados do Centro de Estudos de Opinião Pública CESOP-UNICAMP. 2006. Disponível em:

<http://www.cesop.unicamp.br/site/htm/busca/php>. Acesso em: 14 abr. 2009.

FAORO, Raymundo. Os Donos do Poder: Formação do Patronato Político Brasileiro. Rio de Janeiro/Porto Alegre/São Paulo: Editora Globo, 1958.

FEREJOHN, John; SHIPAN, Charles. Congressional Influence on Bureaucracy. The Journal of Law, Economics \& Organization, Oxford, v. 6, p. 1-20, jan. 1990.

HOLANDA, Sérgio B. Raízes do Brasil. Rio de Janeiro: José Olímpio Ed., 1936.

HUNTINGTON, Samuel. A Terceira Onda. São Paulo: Record, 2000.

INEA. Instituto Anti-Corrupción en América Latina (INEA). 2006. Disponível em:

<http://www.ineaestudiosanticorrupcion.org/page_1117909884039.html>.

Acesso em: 25 jan. 2011.

INGLEHART, Ronald. Cultura e democracia. In: HARRISON, Lawrence; HUNTINGTON, Samuel (Orgs.). A Cultura Importa. Rio de Janeiro: Record, 2002. p. $133-154$.

JIMENEZ, Alfredo R. Las formas modernas de la política: estudio sobre la democratización de América Latina. 2. ed. Mérida: Centro de Investigaciones de Política Comparada, 2008.

LAPOP. Banco de dados: Brasil 2007. 2007. Disponível em: <http://www.vanderbilt.edu/lapop/>. Acesso em: 08 jun. 2010.

LATINOBARÓMETRO. Bancos de dados: 1996, 1998 a 2005. Disponível em: <http://www.latinobarometro.org >. Acesso em: 12 jun. 2008. 
LAWSON, Kay; MERKL, Peter. When parties fail: emerging alternative organizations. Princeton: Princeton University Press, 1988.

LECHNER, Norbert. Tres formas de coordinación social. Revista de la CEPAL, Santiago de Chile, v. 61, n. 39, p. 7-17, abr. 1997.

MAINWARING, Scott. Sistemas partidários em novas democracias: o caso do Brasil. Rio de Janeiro: Editora FGV, 2001.

MAINWARING, Scott; BEJARANO, Maria; PIZARRO, Eduardo. The crisis of democratic representation in the Andes. Stanford: Stanford University Press, 2006.

MAINWARING, Scott; SCULLY, Timothy. Introduction: party systems in Latin America. In: MAINWARING, Scott; SCULLY, Timothy (Eds). Building democratic institutions: parties and party systems in Latin America. Stanford: Stanford University Press, 1995. p. 1-34.

. Latin America. Journal of Democracy, Washington D. C., v. 19, n. 3, p. 113-127, jul. 2008.

MARTINS, Paulo H. Cultura autoritária e aventura da brasilidade. In: BURITY, Joanildo (Org.). Cultura e identidade: perspectivas interdisciplinares. Rio de Janeiro: DP\&A Editora, 2002. p. 65-104.

NORRIS, Pippa. The News Media and Democracy. In: BARTLE, John; DYLAN, Griffiths (Eds.). Political Communications Transformed: from Morrison to Mandelson. Basingstoke: Palgrave Publish New York, 2001. p. 163-180.

NUNES, Edson. A Gramática Política do Brasil: clientelismo e insulamento burocrático. Rio de Janeiro: Jorge Zahar Editores, 1997.

NUPESAL. Banco de Dados: Pesquisa de Cultura Política em Porto Alegre, 2000.

Banco de Dados: Pesquisa de Cultura Política em Porto Alegre, 2005.

O'DONNELL, Guillermo. Democracia delegativa? Novos Estudos CEBRAP, São Paulo, n. 31, p. 25-40, out. 1991.

Democracy, law and comparative politics. Studies in Comparative International Development, Providence, v. 36, n. 1, p. 7-36, jun.-jul. 2001. 
PAYNE, J. Mark; ZOVATTO, Daniel; FLORES, Fernando Carrillo; ZAVALA, Andrés Allamand. Democracies in development: politics and reform in Latin America. Baltimore: John Hopkins University Press, 2002.

POGUNTKE, Thomas; SCARROW, Susan E. The politics of anti-party sentiment: introduction. European Journal of Political Research, Norwell, v. 29, n. 3, p. 257-262, apr. 1996.

PRZEWORSKI, Adam; ALVAREZ, Michael; CHEIBUB, José; LIMONGI, Fernando. Democracy and development: political institutions and well-being in the world, 1950-1990. UK: Cambridge University Press, 2003.

PUTNAM, Robert. Bowing Alone: the collapse and revival of American community. New York: Simon \& Schuster, 2000.

REIS, Elisa P. Governabilidade e solidariedade. In: VALADARES, Lúcia; COELHO, Magda (Orgs.). Governabilidade e pobreza no Brasil. Rio de Janeiro: Civilização Brasileira, 1995. p. 49-64.

. Processos e escolhas: estudos de sociologia política. Rio de Janeiro: Contracapa, 1998.

SAMUELS, David. Determinantes do voto partidário em sistemas eleitorais centrados no candidato. Dados, Rio de Janeiro, v. 40, n. 3, p. 493-533, 1997.

SÁNCHEZ-PARGA, José. Transformaciones del conflicto, decline de los movimientos socials y teoria del desgobierno. Ecuador Debate, Quito, n. 53, p. 19-39, ago. 2001.

SANTOS, Wanderley G. dos. Crime e castigo: partidos e generais na política brasileira. Rio de Janeiro: IUPERJ, 1987.

SoUZA, Maria do Carmo C. Estado e partidos políticos no Brasil (1930 a 1964). São Paulo: Alfa-Omega, 1976.

THOMPSON, John. Ethics in Congress: from individual to institutional corruption. Washington: The Brookins Institution, 1995.

TORCAL, Mariano. Political disaffection and democratization history in new democracies. Working Paper, Juan March Institute, Madrid, 308, out. 2003.

TRANSPARENCY INTERNATIONAL. Global Corruption Barometer. 2004. Disponível em: <http://www.transparency.org/>. Acesso em: 12 jan. 2010. 
DOSSIÊ CAPITAL SOCIAL E COMPORTAMENTO ELEITORAL

VALELLY, Rick. Who needs political parties? The American prospect, Washington D. C., v. 11, n. 18, p. 48-50, nov. 2002.

WEBER, Max. Economia e Sociedade: fundamentos da sociologia compreensiva. Brasília: Ed. da Unb, 2004. 2 v.

Texto recebido em 28/04/2011. Aprovado em 14/06/2011.

114 REVISTA DEBATES, Porto Alegre, v.5, n.1, p. 89-114, jan.-jun. 2011. 